\title{
As características sistemáticas de recursos multimodais mobilizados por uma criança com TEA em turnos de fala corporificados ${ }^{1}$
}
The systematic characteristics of multimodal resources mobilized by a child with ASD in embodied turn-takings

Douglas Vidal SANTIAGO*

\begin{abstract}
RESUMO: Este artigo visa a analisar os recursos multimodais (fala, gesto, objetos, movimentos corporais) mobilizados por Luiza, pseudônimo de uma criança com diagnóstico de Transtorno do Espectro do Autismo (TEA), e por seus interlocutores familiares durante $\mathrm{o}$ processo de construção da atenção conjunta em uma interação cotidiana em ambiente nãoinstitucional. Para tanto, focamos em abordagens que enfatizam os aspectos multimodais da linguagem, destacando a articulação fina entre as produções verbais e gestuais mobilizadas por esse sujeito com TEA como formas linguísticas que produzem uma complexidade estrutural semântica e pragmática que pode contribuir para os estudos sobre as relações entre gestos e gramática, em

ABSTRACT: This paper aims to analyze the multimodal resources (speech, gestures, objects and body movements) mobilized by Luiza, pseudonym of a child diagnosed with Autism Spectrum Disorder (ASD), and her family members during the process of joint attention in an everyday interaction in a noninstitutional environment. To that end, we focus on approaches that emphasize the multimodal aspects of language, highlighting the fine articulation between verbal and gesture productions mobilized by this individual with ASD as linguistic forms that produce semantic and pragmatic structural complexity that may contribute for the studies on relations between gestures and grammar, in search of a Complex Multimodal (gesture/posture
\end{abstract}

\footnotetext{
${ }^{1}$ Este artigo consiste da apresentação resumida dos achados de pesquisa da Dissertação de Mestrado "Gestalt multimodal: análise da coordenação de gestos e língua nas interações de uma criança com TEA (Transtorno do Espectro do Autismo)" defendida em 24 de agosto de 2018 com financiamento da Coordenação de Aperfeiçoamento de Pessoal de Nível Superior (Capes). Deixo aqui meus agradecimentos à doutoranda Caroline Cots por compartilhar comigo o seu Corpus para Estudo da Linguagem no Autismo (Cela) e a minha orientadora Fernanda Miranda da Cruz pelas inúmeras contribuições feitas ao longo desse processo.

CAAE: 76350517.1.0000.5505; Número do Parecer: 2.967.471; Projeto CEP/UNIFESP: n: 1119/2017; projeto aprovado em 04 de Outubro de 2017.

" Mestre em Letras - Universidade Federal de São Paulo (UNIFESP). ORCID: https://orcid.org/00000002-0998-9623. douglasvidalltrs@gmail.com
} 
busca de uma Gestalt (padrão) Multimodal (gesto/postura + fala) Complexa no repertório comunicativo dessa criança. Os achados da análise empreendida sugerem que embora possua algumas restrições do ponto de vista dos recursos verbais, Luiza os mobiliza de modo articulado a recursos não-verbais para construir e para participar da situação interativocomunicacional. Destarte, a investigação multimodal possibilitou dar visibilidade a uma gama de recursos linguísticos e gestuais empregados por essa criança.

PALAVRAS-CHAVE: Análise Multimodal. Transtorno do Espectro do Autismo. Gestalt Multimodal Complexa.
+ speech) Gestalt (standard) in the communicative repertoire of this child. The findings of the analysis suggest that, although having some restrictions from the point of view of verbal resources, Luiza mobilizes them in articulated way to non-verbal resources to build and participate in the interactivecommunicational situation. Therefore, the multimodal research made it possible to give visibility to a range of linguistic and gestural resources employed by this child.

KEYWORDS: Multimodal Analysis. Autism Spectrum Disorder. Complex Multimodal Gestalt.

\section{Considerações iniciais}

O presente artigo visa a investigar os recursos interacionais multimodais, tais como: fala, gestos, objetos, movimentos corporais, mobilizados por uma criança, de pseudônimo Luiza, diagnosticada com Transtorno do Espectro do Autismo (doravante TEA) e por seus interlocutores familiares durante os processos de construção conjunta de ações em uma situação conversacional em ambiente familiar. Durante o período de geração do dado audiovisual que compõe esta pesquisa, Luiza tinha idade entre 10 anos e 10 meses a 12 anos e 3 meses.

O TEA é descrito clinicamente como uma condição que afeta o desenvolvimento neurocognitivo e compromete, dentre outros aspectos, o engajamento do sujeito na construção conjunta da atenção, das ações e na participação em interações sociais (LAI; LOMBARDO; BARON-COHEN, 2014). Nesse transtorno, o processo de desenvolvimento linguístico é descrito como comprometido, caracterizando-se por alterações que afetam a linguagem, os processos de socialização, a comunicação e o aprendizado. Do ponto de vista dos estudos linguístico-interacionais que se interessam pela interação social que construímos através da linguagem, um 
comprometimento do engajamento social afeta não apenas o sujeito com TEA, mas também os seus interlocutores.

O comprometimento do engajamento social afeta as formas pelas quais os sujeitos com autismo e seus interlocutores, familiares, próximos ou profissionais, mobilizam seus recursos na construção intersubjetiva das ações ou nas tentativas de construção conjunta das mesmas. Nesse sentido, podemos supor que, nas interações envolvendo sujeitos com autismo, encontramos formas diversas de interação, incluindo tanto padrões interativos mais conhecidos e praticados socioculturalmente, como outras formas que emergem das circunstâncias situadas e locais decorrentes do autismo, incluindo aqui as competências, as limitações e as (im)possibilidades de todos os participantes envolvidos (CRUZ, 2017b, p. 159).

Levando esses aspectos em consideração, pretendemos elencar e dar visibilidade às variabilidades funcionais que unidades linguístico-gestuais, interacionais, semânticas e sintaticamente estruturadas exercem a depender do contexto situacional em que ocorrem, levando em conta, assim, à recorrência sistemática destes no repertório comunicacional de Luiza. Observamos, para isso, os enunciados verbais produzidos por esse sujeito diagnosticado com TEA coordenados com os recursos gestuais, uma vez que aqueles poderiam receber uma interpretação de fala elíptica, termo cunhado também como fala telegráfica ou fala reduzida (KLEPPA, 2014) ou incompleta se considerados apenas durante a ação de falar verbalmente algo com o outro. Contudo, neste estudo os aspectos verbais produzidos são submetidos a uma análise multimodal, ou seja, a uma investigação que leva em conta uma coordenação muito articulada, durante a própria atividade de fala, de unidades de distintas naturezas semióticas.

É importante salientar que esses recursos multimodais, como têm apontado Cruz (2017a) com base nos trabalhos de Goodwin (2010), de Levinson e Holler (2014) e de Mondada (2016), podem ter uma materialidade sonora ou visual, uma dimensão semiótica linguística ou corporal e compreendem aspectos como fonética, sintaxe, 
léxico, gestos, olhares, mímicas faciais, movimentos de cabeça, posturas do corpo, movimentos das mãos, objetos e artefatos do mundo material, dentre outros.

Os dados linguístico-interacionais referentes às produções verbais de Luiza, quando submetidos a uma exploração alicerçada na perspectiva multimodal, permitem-nos observar como tais enunciados estão correlacionados a algum gesto. Ademais, a estrutura linguístico-gestual torna-se central para compreendermos analiticamente como essa criança faz para ser entendida e para demonstrar suas intenções sociocomunicativas em uma determinada situação interativa. Noutras palavras, destacaremos na análise como as produções verbais elípticas, aparentemente incompletas ou sem sentido se analisadas apenas do ponto de vista de sua construção verbal, exercem papéis sintáticos, semânticos, comunicativos e interacionais. Dessa forma, a descrição e a análise multimodal podem oferecer muitos ganhos para a compreensão dos distintos recursos semióticos mobilizados por esse sujeito com TEA, tais recursos estão estruturados de acordo com uma gramática multimodal, isto é, que reconhece certos padrões regulares de usos de formas linguístico-verbais e gestuais.

Para a condução desses propósitos, tomamos como base a noção de ação conjunta formulada por Tomasello (1995). A ação conjunta refere-se à capacidade de compreender a intenção de outra pessoa em relação ao seu estado de atenção, distinguindo os interlocutores como agentes intencionais (TOMASELLO, 1995, 2009). No caso mais específico dos sujeitos com TEA, identifica-se uma dificuldade de apreensão de conceitos semântico-lexicais (LIMA; REHBERG, 2016), pois suas participações nos diversos jogos interacionais e nas práticas sociais podem estar comprometidas pelas alterações no engajamento afetivo e na leitura e compreensão das intenções do(s) outro(s). Noutros termos, “[...] indivíduos com TEA envolvem-se frequentemente em situações mal-entendidas porque, apesar de eles conhecerem a palavra, não sabem o seu significado e não sabem empregá-la em diferentes situações" (LIMA; REHBERG, 2016, p. 78). 
Segundo Brait (2010), nós organizamos a fala de maneira a compreender e a se fazer compreendido, utilizando o instrumental linguístico (no seu conceito de sistema de normas e de estratégias de uso) e, como complementa Mondada (2016), dos turnos de fala corporificados combinados com regras culturais, sociais e situacionais. Assim, na análise da dinâmica interacional que selecionamos para enfoque neste estudo, levamos em consideração a situação contextual, as estratégias e os recursos utilizados por todos os participantes (neurotípicos ou não) envolvidos na interação.

O dado transcrito, que analisaremos neste artigo, foi gerado por registros audiovisuais de situações interativas naturalísticas das quais Luiza participa em seu ambiente domiciliar com interlocutores que compõem parte de suas rotinas cotidianas. O registro audiovisual foi realizado por Cots (2015) durante sua pesquisa de iniciação científica. Todos os registros audiovisuais realizados durante essa pesquisa compõem o Cela - Corpus para Estudo da Linguagem no Autismo.

Por fim, os achados da análise empreendida neste estudo sugerem que embora possua algumas restrições do ponto de vista dos recursos verbais, Luiza os mobiliza de modo articulado a recursos não-verbais para construir e para participar da situação interativo-comunicacional. Sendo assim, os achados permitem considerar a produtividade de analisar o dado em busca de Gestalts (padrões) Multimodais (gestos/postura + fala) identificados no repertório sociointeracional dessa criança, dados que possibilitam dar visibilidade a uma gama de recursos verbais e não-verbais empregados pelo sujeito.

\section{A interação social nos TEAs sob o prisma da multimodalidade}

A análise empreendida neste artigo propõe corroborar um repertório de dados de práticas corporificadas e de descrições multimodais da fala-em-interação envolvendo crianças autistas. Nessa linha de investigação, buscamos colaborar com os estudos que têm de se dedicado à investigação multimodal das interações 
(MONDADA, 2012, 2016) envolvendo crianças autistas (ANDRADE, 2017; CRUZ, 2017a, 2017b, 2018) com ênfase em aspectos específicos, como os risos (GLENN, 2003; AUBURN; POLLOCK, 2013), os gestos de apontar (DINDAR; KORKIAKANGAS; LAITILA; KÄRN̈̈, 2016) e os direcionamentos do olhar (FENG, 2014; KORKIAKANGAS, 2014).

É dentro da perspectiva linguístico-interacional que situamos nossa pesquisa. A contribuição que gostaríamos de oferecer aos estudos sobre o autismo é pensar as produções de Luiza com base no conceito de Gestalt Multimodal Complexa (AUER, 2009, 2015; SELTING, 2000, 2005; MONDADA, 2014a, 2014b, 2016).

A abordagem de uma perspectiva linguística sociointeracional pode oferecer subsídios importantes para a compreensão da forma como os sujeitos com TEA interagem e como os outros interlocutores interagem com eles. Esses subsídios podem ser considerados em pesquisas clínicas ou mesmo em práticas diagnósticoterapêuticas, embora nosso estudo não dê conta, em seu escopo e em sua filiação teórico-metodológica, dessas dimensões.

Mais especificamente, nossa contribuição está em construir uma coleção de dados multimodais com as produções de Luiza extraídas de uma interação cotidiana (ver seção 4.2. Excerto 01: CELA09_2015_T - transcrição), com o fim de elencar e dar visibilidade às variabilidades funcionais que as unidades linguístico-gestuais exercem a decorrer do contexto situacional em que se desenrolam.

\subsection{Gestalt Multimodal Complexa e alguns aspectos multimodais de interações envolvendo uma criança com diagnóstico de TEA}

A hipótese de uma Gestalt Multimodal Complexa envolve, segundo Mondada (2014b), formas mais convencionais, como é o caso das estruturas linguísticogramaticais (fonológicas, morfológicas, sintáticas, semânticas e pragmáticas), mais situadas (ações corporais) e recursos a objetos materiais presentes no ambiente da interação. 
Em termos analíticos estamos interessados em dar conta de uma descrição possível de padrões interativos encontrados em uma interação da qual participa Luiza e seus familiares. A criança com TEA mobiliza recursos verbais e não-verbais em suas interações. Na sua descrição de perfil comunicacional, oriunda dos próprios dados do Cela e do relato de seus familiares, há a recorrência muito frequente de algumas formulações verbais em seu repertório linguístico-comunicacional em contextos mais variados de interação e de intenções comunicacionais. As produções verbais são coconstruídas com os gestos, os recursos visuais e os objetos materiais do ambiente. Para tratar tais ocorrências, buscaremos descrever a organização da fala-em-interação fundamentando-nos em uma abordagem corporificada dos turnos de fala estruturantes das interações em questão e, para isso, adotaremos a noção de Gestalt Multimodal Complexa (MONDADA, 2014a, 2014b, 2016) como forma de descrever os padrões sociointeracionais encontrados.

A noção de Gestalt nos estudos linguístico-interacionais surgiu com a finalidade de explorar e de compreender aspectos linguísticos que estruturam os turnos de fala, com base na análise de dados naturalísticos em situações de interação, caracterizandose, inicialmente, como construções linguísticas locais e situadas interacionalmente (AUER, 2009, 2015; SELTING, 2000, 2005; MONDADA, 2014a, 2014b, 2016).

Mondada (2014b) desenvolve essa noção levando em conta a ecologia que constitui a atividade interacional (GOODWIN, 2010) e propõe uma ampliação do termo Gestalt para uma Gestalt Multimodal Complexa (traduzido do inglês Complex Multimodal Gestalt), isto é, padrões linguístico-interacionais construídos de recursos multimodais corporificados.

Contrary to interactions analyzed within an exclusive focus on talk, this implies a plurality of temporalities and sequentialities progressing at the same time within the local emergent design of complex multimodal Gestalts (Mondada 2014a, 2014b). Sequentiality is a less linear phenomenon than it appears just on the basis of talk; it relies on 
subtle ways of arranging and adjusting prior and next actions in real time, among differing, and yet coordinated, simultaneous multimodal conduct reflexively intertwined together (MONDADA, 2016, p. 12).

Mondada (2014b) defende assim que a descrição gramatical da interação deve integrar aspectos múltiplos e dinâmicos, tais como: fala², gesto, olhar, expressão facial, postura e movimento corporal multimodalmente. Desse modo, é preciso levar em consideração uma corporeidade sequencial da organização da ação e uma estruturação multimodal dos turnos de fala, pois a interação e mesmo a organização das estruturas sintáticas dos turnos de fala são sensíveis à orientação corporal dos coparticipantes (traduzido do inglês recipient-oriented) e ao meio ambiente material-físico e imediato em que estão os falantes. Desse ponto de vista, o estudo da interação social deve compreender como recursos multimodais - incluindo língua e movimentos corporais - são holísticos e situadamente utilizados para construir a ação humana.

\section{Empreendimento metodológico: construção do Cela e seleção do dado para análise}

Para registro das situações interativas das quais Luiza participa foi adotado o método de instalação de uma câmera fixa em locais de interações junto a familiares que fazem parte de suas rotinas cotidianas. O Cela (Processo Comitê de Ética da Universidade Federal de São Paulo, no. CAAE: 40889115.5.0000.5505 CEP: 0052/2015 e 1172/2016) tem aproximadamente 6h de gravações audiovisuais selecionadas para tratamento e transcrição de um total de registros audiovisuais de aproximadamente 60 horas de filmagens.

Os registros de situações naturais espontâneas relativas às interações das quais participa Luiza foram realizados entre maio de 2014 e outubro de 2015, período em

\footnotetext{
2 Conforme Enfield (2005 apud CRUZ, 2017a), consideramos a fala uma atividade corporificada, levando em conta uma diferença entre a modalidade vocal-oral, que inclui língua falada/fala e aspectos prosódico-entonacionais, e a modalidade visuo-espacial, que inclui gestos tais como: direcionamentos de olhar, postura corporal e movimentos corporais.
} 
que a criança tinha de 10 anos e 10 meses a 12 anos e 03 meses de idade. Durante as filmagens, o ângulo da câmera procurou privilegiar posições que contemplassem focos mais abertos, capazes de registrar a interação como um todo e não exclusivamente Luiza. Para compor um corpus dessas interações mais próximas de uma espontaneidade, nenhum teste ou tarefa foi solicitado aos participantes.

A escolha do sujeito participante para composição do Cela se deu, conforme observa Cots (2015), devido ao acesso que este tinha à rotina e ao cotidiano de Luiza. A pesquisadora pôde observar as interações da criança diagnosticada com TEA de forma não invasiva, configurando-se então como participante e observadora das situações interativas.

Diagnóstico: de acordo com relatos da mãe, até os 2 anos Luiza ainda não tinha emitido nenhuma palavra, não engatinhava, pouco se interessava pelos objetos ao seu redor e chorava constantemente. Esses foram os motivos que a levou a procurar ajuda médica. Após acompanhamento clínico, exames e observação, Luiza foi diagnosticada com TEA aos 4 anos, no Instituto de Psiquiatria do Hospital das Clínicas, em São Paulo.

Características linguístico-interacionais observadas durante os registros audiovisuais: após a visualização dos registros do CELA, pudemos notar que o repertório lexical de Luiza é restrito e composto em sua maioria por nomes e verbos, contudo ela também recorre a recursos não-verbais, como gestos de mão, movimentos corporais e direcionamentos de olhar e torso, para participar ativamente das interações familiares.

Escolarização: desde os 4 anos Luiza frequenta regularmente a escola especial, na qual tem a possibilidade de interagir também com crianças diagnosticadas com TEA que apresentam um quadro de desenvolvimento próximo ao apresentado por ela. De acordo com relato dos familiares, Luiza apresenta uma boa inserção no espaço escolar-institucional e um bom relacionamento interpessoal. Na escola, utilizou por algum período a comunicação por troca de figuras (Picture Exchange Communication System PECS) para interagir com professores e profissionais. A criança ainda não é alfabetizada. 
Acompanhamento clínico-terapêutico: Luiza passou por acompanhamento fonoaudiólogo dos 4 aos 6 anos. Desde o diagnóstico tem recebido acompanhamento psiquiátrico a cada 3 meses no Hospital das Clínicas (São Paulo) e, desde os 9 anos tem acompanhamento psicopedagógico particular de duas a três vezes por semana para a alfabetização. Também passou por acompanhamento com Terapeutas Ocupacionais e Musicoterapeutas.

Outras atividades familiares pertinentes para o desenvolvimento sociointeracional de Luiza: a família costuma viajar bastante, o que possibilitou o contato de Luiza com outros espaços e organizações sociais e a interação com pessoas que não faziam parte do seu cotidiano. (COTS, 2018, p. 66-67).

\subsection{Notação de transcrição}

Adotamos neste estudo a proposta de convenção de transcrição multimodal de Mondada (2012, 2016). A transcrição que será apresentada neste artigo procura dar conta da integração articulada de várias modalidades (verbais e gestuais), dentro de uma dinâmica sequencial e temporal complexa que compõe as ações construídas intersubjetivamente pelos participantes (MONDADA, 2012, 2016; CRUZ, 2017a, 2017b).

Nessa convenção de transcrição multimodal, Mondada (2012) transcreve a trajetória dos gestos inspirada na notação proposta por Goodwin (1981) e por Kendon (2004) e sua correlação temporal com a produção verbal. O princípio de base dessa transcrição é alinhar as coordenações, as simultaneidades e as sincronias de gestos e de fala de forma a dar visibilidade aos aspectos (problemas e questões) para os quais se orientam os participantes durante a construção da interação com o outro (CRUZ, 2017a). 
Apresentamos neste artigo uma versão traduzida e reduzida da notação de transcrição multimodal com base na tradução da notação de $\operatorname{Mondada}^{3}(2012,2016)$ realizada por Cruz (2017a). Acrescentamos a essa versão alguns símbolos e inserções de outra natureza para os fins deste estudo.

\subsection{Informações gerais}

a) Nessa convenção, Mondada (2012) transcreve a trajetória dos gestos inspirada na notação proposta por Goodwin (1981) e por Kendon (2004).

b) Cada participante é indicado por três letras iniciais que indicam seu nome (CLA para Clara; GUS para Gustavo; LUI para Luiza). As letras iniciais em maiúsculo indicam a fala (CLA, GUS, LUI). As letras iniciais em minúsculo indicam gestos (cla, gus, lui).

c) Em caso de referência ao participante no interior do turno de fala por outro interlocutor, opta-se pelo uso das iniciais indicadas dos pseudônimos correspondentes. No texto de análise do dado, entretanto, opta-se pelo uso do pseudônimo.

d) Cada linha da transcrição é numerada e não corresponde necessariamente aos turnos de fala.

e) Para distinguir, do ponto de vista gráfico-visual, as falas dos gestos, aquelas são apresentadas em negrito e a descrição destes últimos em itálico.

\footnotetext{
${ }^{3}$ A convenção de Mondada (2016) pode ser acessada, nas versões em inglês e em francês pelo seguinte endereço eletrônico:

https://franz.unibas.ch/fileadmin/franz/user upload/redaktion/Mondada conv multimodality.pdf.

Acesso em 06 de fev. de 2018.
} 


\subsection{Aspectos linguístico-verbais}

Xxx segmento ininteligível.

\& continuação do turno de fala pelo mesmo locutor após uma quebra da linha da transcrição.

(.) micro pausas, inferiores a 0,3 segundos, não medidas.

(0.4) pausas medidas com ajuda do software Elan versão 5.0.0-alpha.

= fala colada.

: alongamento silábico.

.h marca a inspiração do locutor.

/ entoação ascendente.

\entoação descendente.

// entoação de pergunta (ascendente).

Sublinhado ênfase particular (intensidade, acento).

MAIÚSCULA volume forte de voz.

$\circ{ }^{\circ}$ volume baixo, murmúrio de voz.

$\uparrow$ subida na curva entoacional, em sílabas nucleares posicionadas antes da sílaba.

$\downarrow$ descida na curva entoacional, em sílabas nucleares.

(( xxxxx )) anotação do contexto situacional.

$\rightarrow$ neutralidade na curva entoacional, em sílabas nucleares.

\subsection{Aspectos gestuais-corporificados}

Os aspectos gestuais-corporificados correspondem à descrição e à marcação de ações como gestos em geral, direcionamentos do olhar, gestos com a mão, posturas corporais e movimentos de cabeça.

Cada participante recebe um símbolo gráfico fixo indicador de seus gestos: Clara $\left.{ }^{*}\right)$; Gustavo $(\Delta)$ e Luiza $(+)$.

+-----+ indicação do início do fim da ação/gesto. Delimitação da ação/gesto descrita relacionada à fala transcrita na linha superior. Cada gesto é descrito de forma breve entre os dois marcadores de delimitação, na linha seguinte a da transcrição da fala correspondente e de forma espacialmente alinhada.

,$+{ }^{*}$ a fala transcrita comporta os símbolos gráficos indicadores de gestos $(+, *$, por exemplo) posicionadas no momento em que são realizados com relação à fala. 
A trajetória dos gestos (GOODWIN, 1981).

----> linha 21 continuação do gesto até a linha 21 do excerto.

---->+ se um gesto continua nas linhas seguintes, sua descrição é seguida de uma flecha que remete ao símbolo que delimita o seu fim.

---->> continuação do gesto até o fim do excerto.

$\gg$ o gesto descrito começa antes do turno de fala.

$(0,4)+(0,8)$ se o gesto começa no meio de uma pausa segmenta-se a pausa.

Trajetória temporal dos gestos: para uma notação da trajetória temporal dos gestos, Mondada (2012) adota as convenções propostas por Goodwin (1981) para direcionamentos do olhar e por Kendon (2004) para gestos.

..... emergência do gesto (preparação).

,'!' fim do gesto (retração).

----- manutenção do gesto (núcleo/ápice).

\subsection{Seleção e organização da coleção de dado para este estudo}

Para o empreendimento analítico deste estudo, selecionamos 1 excerto no qual Luiza e seus interlocutores realizam atividades de estabelecimentos e de manutenção de atenção conjunta durante uma atividade interativa. Neste artigo, apresentamos a análise desse excerto com transcrição multimodal em formato textual realizada no Microsoft Word 2010.

O critério para seleção do excerto procurou corresponder ao objetivo específico da pesquisa de Mestrado, cuja proposta é analisar as unidades linguístico-gestuais semântica e sintaticamente estruturadas que Luiza utiliza para estabelecer a construção da atenção conjunta com seus interlocutores. Assim, buscamos elencar as variabilidades significativas que esse repertório comunicativo corporificado pode exercer simultânea ou coordenadamente com elementos verbais. 
4 Análise da organização multimodal de interações envolvendo uma criança com TEA: Gestalt Multimodal Complexa

No dado selecionado para análise neste artigo, discutiremos as características sistemáticas que identificamos no uso de recursos linguístico-gestuais mobilizados por Luiza em seus turnos de fala construídos multimodalmente.

O excerto será introduzido pela descrição da situação interativa, seguido da transcrição multimodal com inserção de imagens dos registros em vídeo, os quais nos permitem visualizar a organização corporal dos participantes e os detalhes do ambiente interacional, e, por fim, a análise descritiva.

\subsection{Excerto 01 - descrição da situação interativa}

Nessa interação, Luiza está sentada no chão da sala usando o aparelho eletrônico tablet enquanto Clara, sua irmã mais velha, e Gustavo, seu sobrinho de 6 anos, estão deitados em um colchão. Gustavo está de costas para as participantes (vide Figura 1). Luiza inicia um vídeo no aparelho eletrônico e uma música infantil começa a tocar.

Há momentos nessa interação em que Luiza e Gustavo disputam a atenção de Clara. Destacaremos como Luiza se ajusta a essa dinâmica interacional e acompanha as distintas práticas de atenção que se estabelecem, indicando que é sensível aos momentos mais propícios para iniciar seus turnos de fala. 
Figura 1 - Posição corporal dos participantes no início da situação interativa.

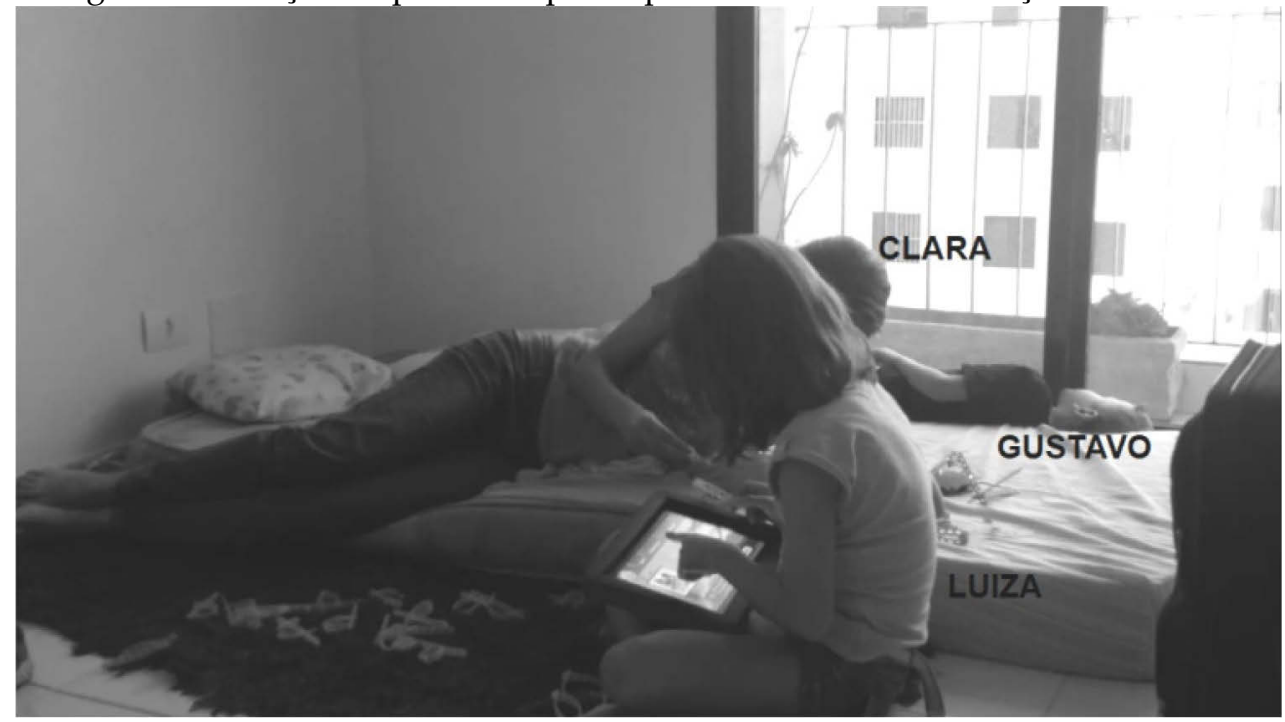

\subsection{Excerto 01: CELA09_2015_T - transcrição}

Corpus: Cela (CRUZ e COTS, 2014 e 2015)

Dado: CELA09 2015 T

Data de trans̄crição: 04/10/2017

Versão da transcrição: 4

Transcritor: Douglas Vidal Santiago

Duração: 47s (14:48-15:35)

Participantes: Luiza (+), Clara (*) e Gustavo $(\Delta)$

Tipo: Conversação espontânea em ambiente familiar

Descrição da sequência interativa: Luiza está sentada no chão da sala usando o tablet enquanto Clara e Gustavo estão deitados em um colchão, estando este último de costas para as participantes. Luiza dá início a um vídeo no aparelho eletrônico e uma música infantil começa a tocar.

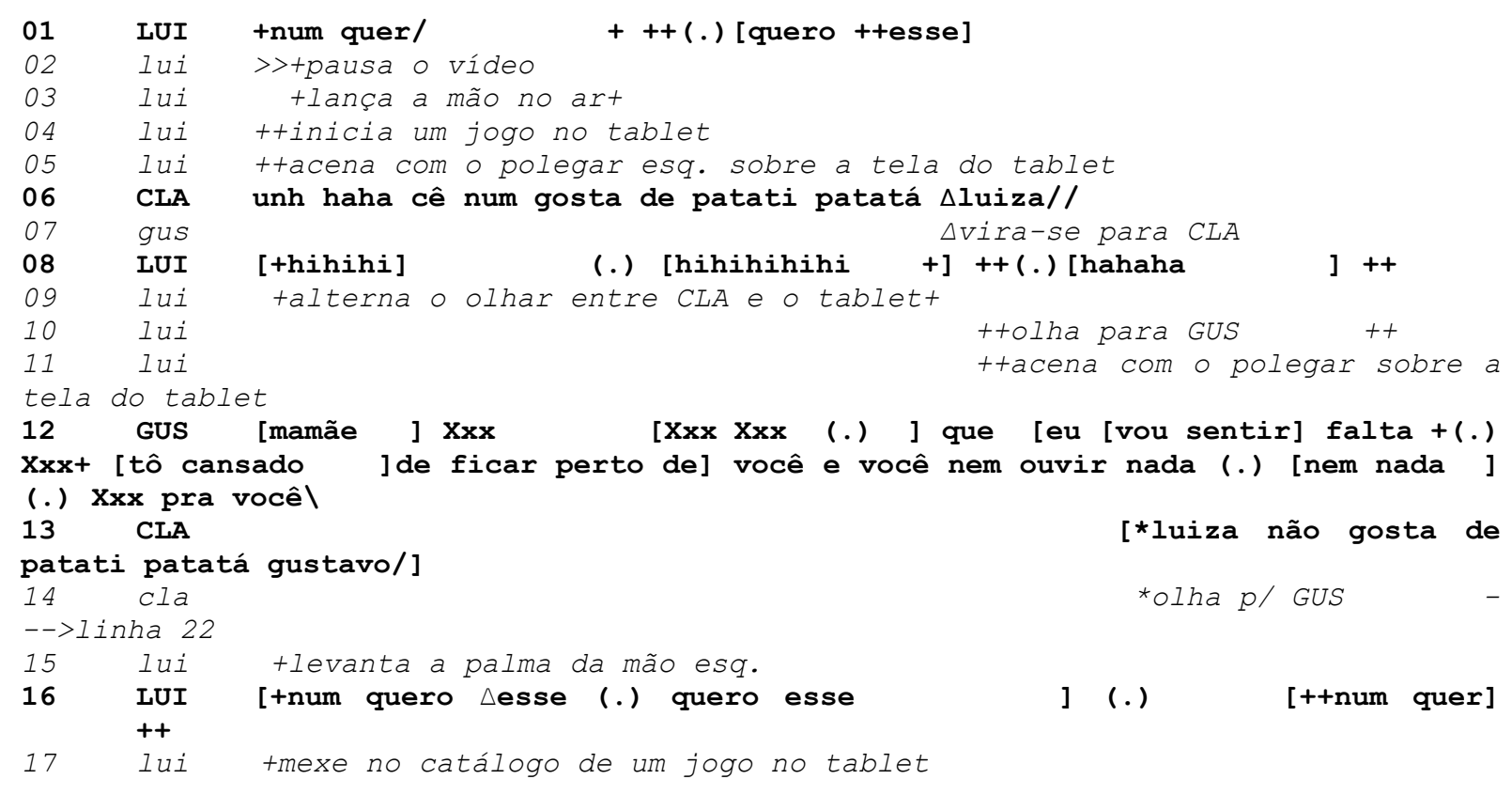




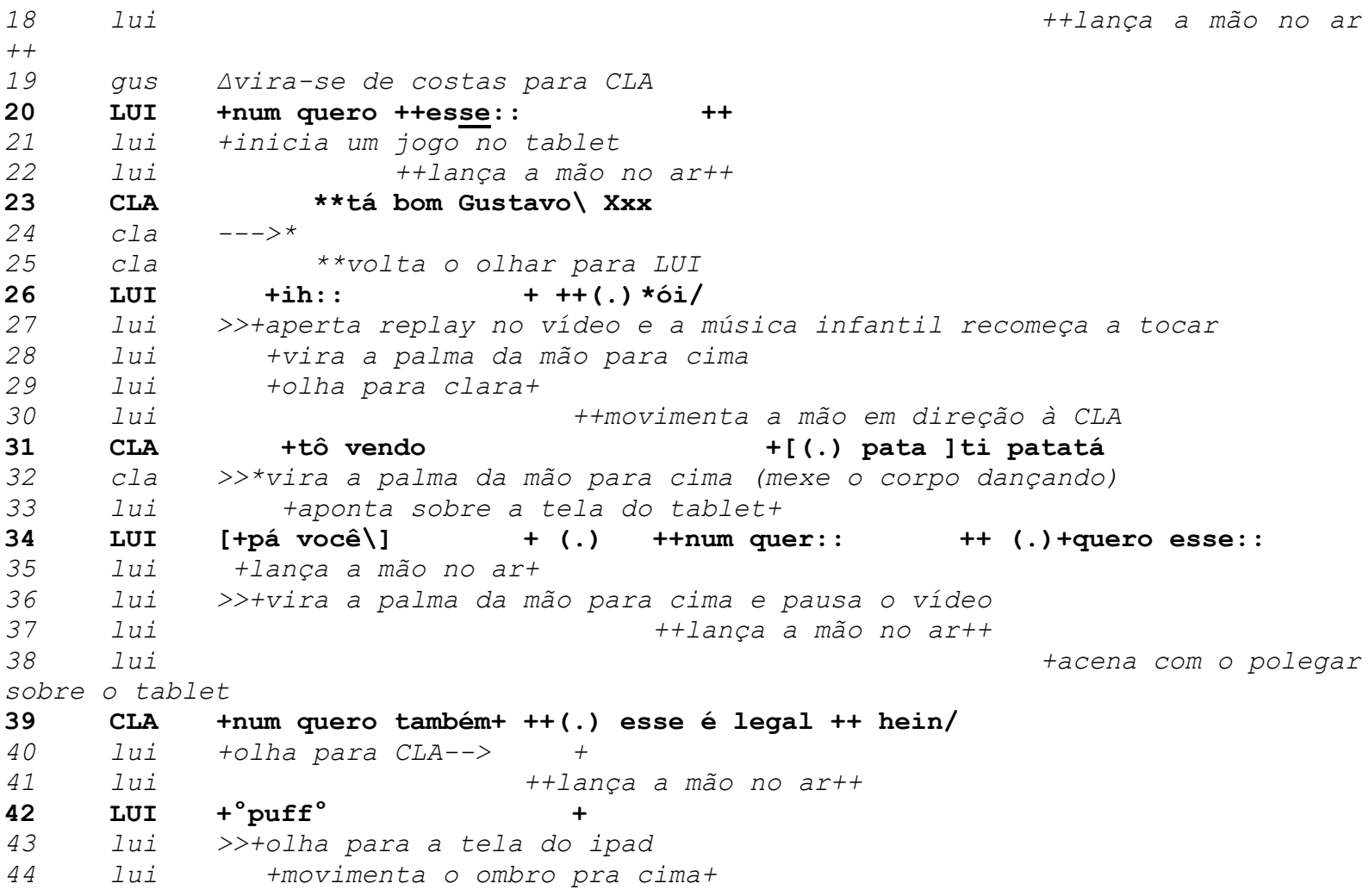

\subsection{As características sistemáticas dos recursos linguístico-gestuais em turnos de fala corporificados}

Ao longo dessa interação, Luiza brinca com um tablet. Na transcrição desse excerto destacamos especificamente os momentos em que Luiza realiza algum gesto com as mãos, significativo para a situação interativa em que está orientada, tais como gestos de lançar a mão no ar, virar a palma da mão para cima, acenar com o polegar sobre a tela do tablet e selecionar uma opção no catálogo de jogos disponíveis no aparelho eletrônico.

Essa transcrição multimodal de uma interação espontânea envolvendo um ambiente material complexo (objeto, gestos, participantes) tenta disponibilizar para a análise algumas características que podem ser sistematizadas dos recursos linguísticogestuais mobilizados pelos interlocutores para chamar a atenção uns dos outros. Conforme Mondada (2005), os recursos multimodais da atividade interacional são explorados de maneira finamente sincronizados e integrados, sendo possível observar 
como os movimentos são localmente estruturados ao longo da atividade interacional. Mostraremos como Luiza acompanha esses movimentos e insere sua participação também coordenada às várias outras ações que compõem a interação. Para isso, selecionamos três coleções de dados multimodais, sendo eles: 1. A coleção de gestos realizados com as mãos; 2. A coleção de risos compartilhados; 3. A coleção dos direcionamentos de olhar.

\subsubsection{Gestos realizados com as mãos}

A modalidade visuo-espacial que inclui gestos (ENFIELD, 2005 apud CRUZ, 2017a) é de grande importância para demonstrar como uma criança com TEA estabelece sequências de atenção conjunta, o que seria difícil evidenciar caso nos limitássemos apenas à modalidade vocal-oral do sujeito participante com autismo. Luiza correlaciona recursos linguístico-gestuais para construir, manter seus turnos de fala e estabelecer uma sequência de atenção conjunta com Clara, tendo como foco a atividade de seleção que realiza no catálogo de um jogo no aparelho eletrônico tablet. Há nesse trecho selecionado uma interação triádica, envolvendo três participantes e um objeto material, empreendida pelo uso de recursos verbais e não-verbais estruturados sistematicamente nos enunciados propostos pela criança com TEA.

Luiza inicia a interação utilizando-se de uma sentença elíptica (linha 01, +num quer/+), cuja cadeia argumental do verbo "querer" é complementada corporalmente com a ação de pausar o vídeo no tablet (linha 02) e o uso do gesto de lançar a mão no ar (linha 03). Luiza não quer assistir ao vídeo que colocou e expressa esse desejo correlacionando recursos linguísticos e gestuais em uma repetição sistemática que se dá ao longo da interação: no início (linhas 01, 02, 03), no meio (linhas 16,18) e no fim (linhas 34, 35, 36, 37), como é possível observar respectivamente nas imagens abaixo. 
Figura 2 - Unidade linguístico-gestual negativa dos três momentos.

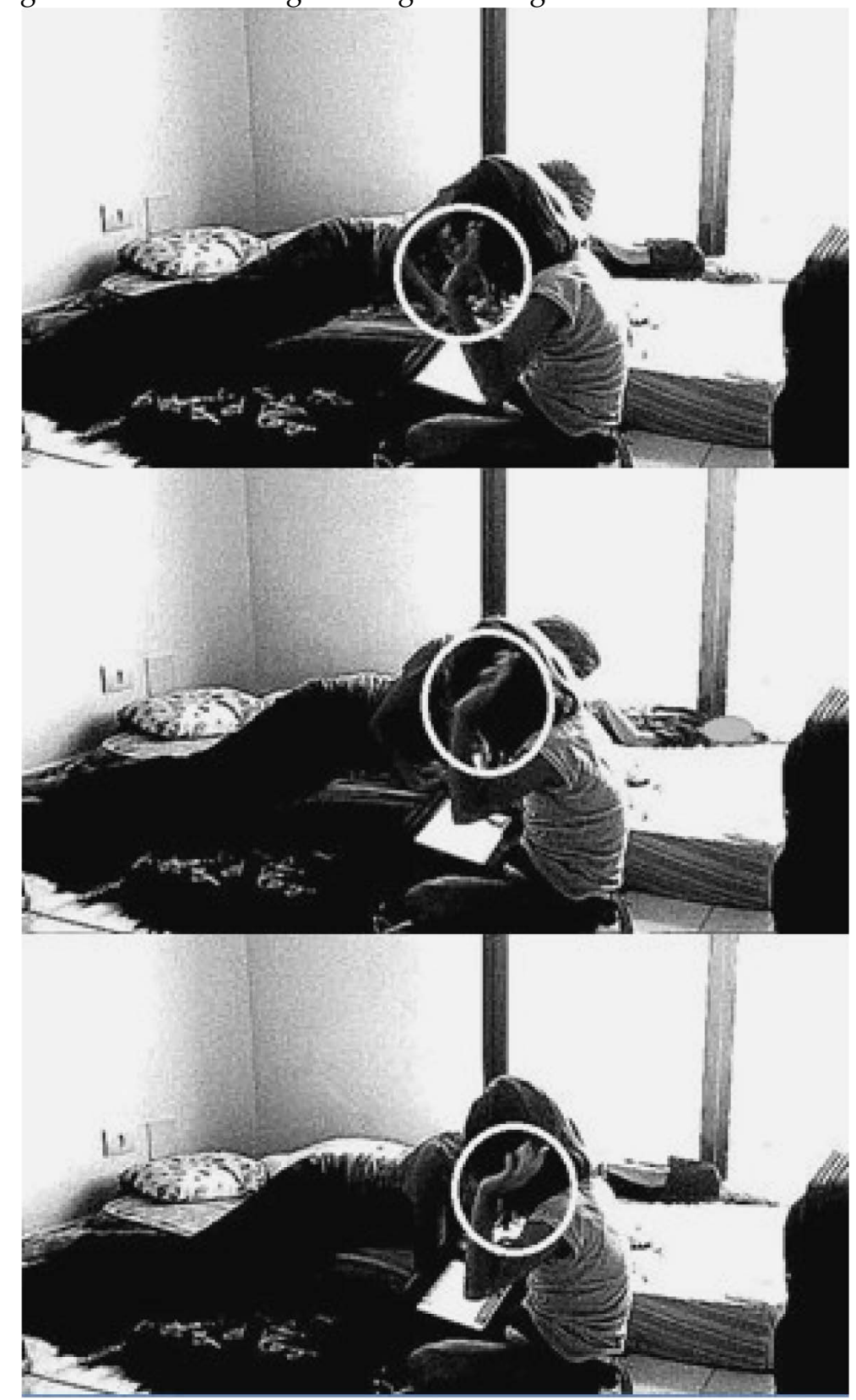

(num quer + ação de pausar o vídeo + gesto de lançar a mão)

Além do emprego dessa unidade linguístico-gestual estruturada (não quer + gestos de lançar a mão), que se configura como uma Gestalt Multimodal Complexa. Para mostrar sua seleção, Luiza faz uso de outro enunciado multimodal (linha 01, quero esse e linha 05, quero esse + gesto emblemático de acenar com o polegar). Essas unidades nos permitem observar a intrínseca relação que Luiza estabelece entre o momento em que 
está em uma atividade de seleção de um jogo e o momento em que seleciona (aponta) gestualmente qual jogo quer.

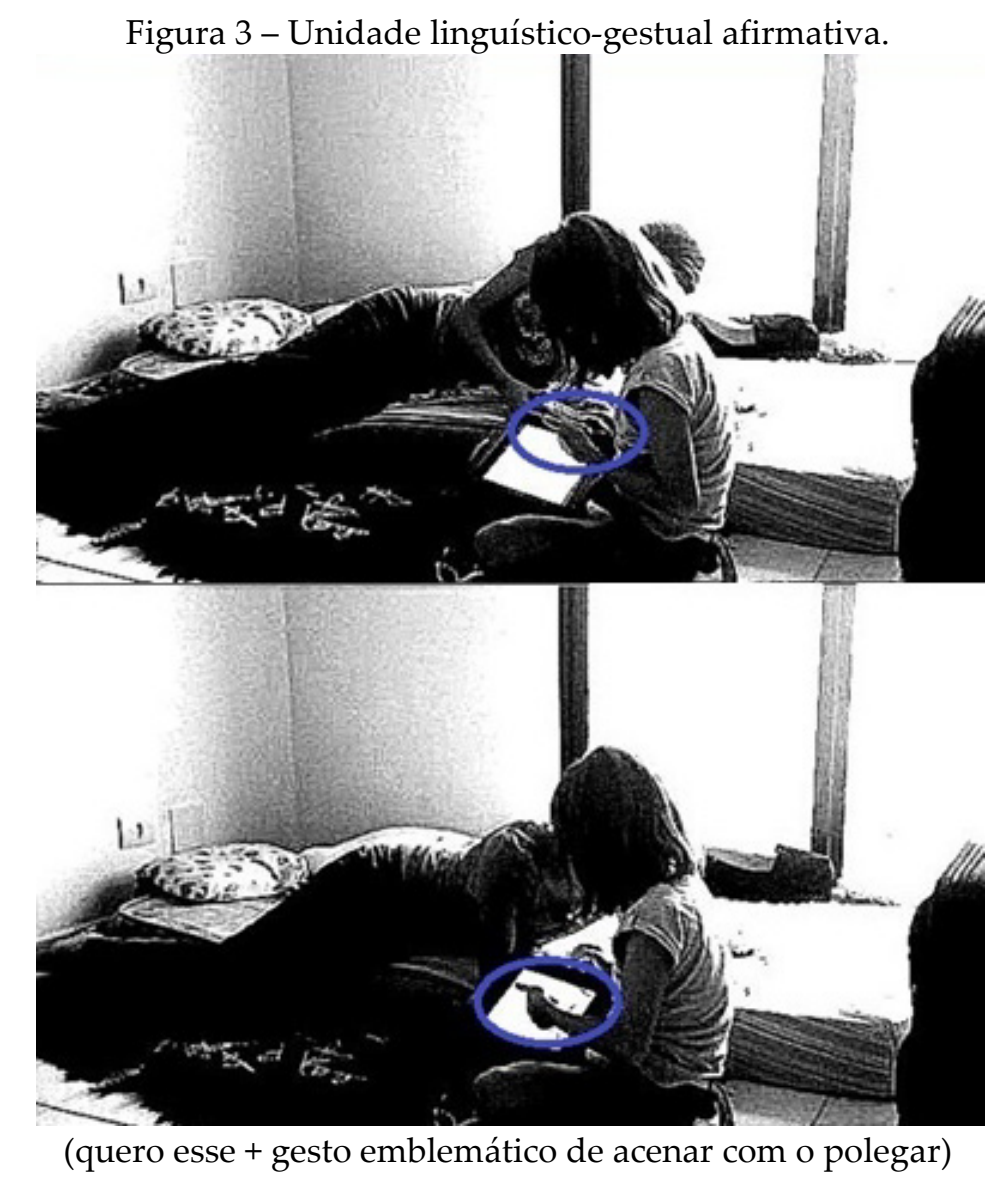

A organização sequencial desses enunciados é configurada pela sintaxe finamente sincronizada com os gestos de apontar sobre a tela do objeto material. Esse é um recurso presente no perfil sociointeracional de Luiza e recorrente no Cela.

Mostraremos a seguir como a interação entre os três (Clara, Luiza e Gustavo) se desenvolve.

\subsubsection{Risos compartilhados}

Clara orienta-se para a atividade de seleção executada por Luiza e responde a essa ação com um riso seguido de uma pergunta polar, tipo de pergunta que pressupõe "sim" ou "não" como resposta, à sua coparticipante (linha 06, unh haha cê num gosta de 
patati patatá luiza//). Luiza ri conjuntamente ao riso de Clara (linha 08, hihihi(.) hihihihihi (.) hahaha).

O riso compartilhado, de acordo com Jefferson (1979 apud GLENN, 2003), vem da sequência de uma pessoa que ri primeiro de modo convidativo para que o outro ria junto. O primeiro riso pode ocorrer correlacionado com a fala ou seguido da conclusão de um enunciado. Além disso, os destinatários podem responder ao riso de várias formas: (a) aceitando ao "convite" e iniciando o riso compartilhado (o que seria pragmaticamente preferível); (b) com silêncio, convidando à busca do riso compartilhado; (c) com uma conversa séria sobre o assunto; ou (d) com a mudança do tópico discursivo quando há uma recusa ao convite para rir junto. Glenn (2003) entende que o riso é um recurso sociointeracional comunicativo presente nas interações humanas cuja ocorrência se dá em padrões sistemáticos sequenciais e socialmente organizados, ocorrendo também finamente coordenado com a fala e com as várias atividades sociais. Noutros termos, o riso é produzido de maneira ordenada e padronizada em determinados momentos com o intuito de realizar ações específicas interacionalmente.

Analisando essa sequência de ação de riso compartilhado, notamos que Clara ri no momento em que Luiza seleciona o que quer ou não no tablet. Luiza responde ao riso, rindo logo em seguida. Esse riso conjunto indica como Clara e Luiza estão voltadas para a mesma atividade, ou seja, para as escolhas que Luiza faz no aparelho eletrônico. No entanto, atenções são requeridas à Clara, único adulto presente na situação durante esta interação. Esta, então, tenta orquestrar a atenção de Gustavo para a atividade de Luiza. Por meio de uma sobreposição de voz ao que Gustavo diz (linha 12), Clara propõe uma entrada de Gustavo no quadro participativo da atividade de Luiza (linha 13, [luiza não gosta de patati patatá gustavo/]), mas há uma recusa ao que interpretamos como um "convite" no momento em que o garoto muda o tópico conversacional para uma sequência de reclamação por atenção (linha 12, mamãe Xxx 
$X x x X x x$ (.) que eu vou sentir falta (.) $x x x$ tô cansado de ficar perto de você e você nem ouvir nada+ (.) nem nada] (.) Xxx pra vocêf). Clara se volta nesse momento para Gustavo. Conjuntamente, Luiza continua sustentando sua atividade interacional com a repetição do padrão: [num quer] + [gesto de lançar a mão].

Quando Clara finaliza esse momento de díade entre ela e Gustavo (linha 23, tá bom Gustavo $\backslash X x x$ ), Luiza chama novamente a atenção de sua irmã mais velha, mas dessa vez acionando como recurso o verbo olhar + gesto de apontar (linha 26, ih ói/). Luiza reativa o foco de atenção compartilhada, apontando sobre a tela do tablet (linha 33).

\subsubsection{Direcionamentos de olhar}

Nesse momento, atentar-nos-emos para o emprego de uma variante do verbo "olhar" na segunda pessoa do singular (linha 25, ói//) mobilizado por Luiza como vocativo para efetivar e estabelecer a atenção compartilhada. Segundo Mondada (2005), “[...] a invocação da visão seria um macroprocedimento para obter a atenção do interlocutor, para tornar acessível e identificável o tópico, para fazê-lo reconhecível enquanto tal e, com frequência, para motivar, justificar e legitimar sua introdução" (op. cit. p. 15). Sendo assim, Luiza endereça a referência à sua coparticipante por meio de práticas sociais multimodais interativas. Ainda, conforme Mondada (2005), as ocorrências do verbo ver/olhar funcionam como um recurso de introdução e de tratamento referencial dos objetos-de-discurso que permitem produzir "como um recurso formal particular de invocação da visão e como procedimento interacional para efetivar a visibilidade dos objetos apontados ou mencionados" (MONDADA, 2005, p. 13).

Andrade (2017) reforça essa reflexão afirmando que para construir a atenção conjunta, o interlocutor precisa ter habilidade para situar e manter o contato visual com o parceiro interacional (op. cit. p. 40). Luiza mostra-se interacionalmente 
competente ao estabelecer e ao fazer a gestão interacional do que se quer como foco (nesse caso, o catálogo do jogo e o vídeo com a música infantil que coloca para tocar). Ademais, a criança é capaz de sustentar seus turnos de fala na interação, mesmo quando Clara, sua interlocutora, volta a atenção para os turnos de fala de Gustavo. Conforme Andrade (2017),

[...] é através da interação face a face [...] que emergem as competências comunicativas, principalmente pela ocorrência da tomada de turnos que consistem a base da cognição social (CARPENTER, NAGEL e TOMASELLO, 1998) e um dos primeiros passos para o desenvolvimento da linguagem (ANDRADE, 2017, p. 38).

Ao observar essa sequência podemos entrar em consonância com o que Andrade (2017) sintetiza sobre atenção conjunta, segundo a qual não pode ser estabelecida quando não há manifestação mútua de interesse entre os sujeitos (MIGUENS, 2006 apud ANDRADE, 2017). Isto é, o mero “ato de seguir o olhar não caracteriza a atenção conjunta como um todo" (ANDRADE, 2017, p. 39), já que o estabelecimento da atenção compartilhada está relacionado ao fato de que dois sujeitos precisam necessariamente prestar atenção a um mesmo objeto e o foco nesse objeto precisa ser manifestado em ambos os indivíduos.

\section{Discussão e sistematização dos achados}

Nesse excerto, destacamos as características sistemáticas de recursos linguísticos e gestuais mobilizados por uma criança com TEA em turnos de fala corporificados.

$\mathrm{Na}$ análise descritiva empreendida neste estudo, com os achados que encontramos, focamos no que Luiza é capaz de fazer em vez do que ela não consegue, assim como é sugerido por Mary Temple Grandi, uma mulher adulta com TEA de alto 
funcionamento. Grandin (1996 apud CRUZ, 2018), cientista e autista, formula a frase célebre: "eu não penso por palavras, eu penso por imagens".

Temple insiste na impossibilidade de haver apenas um tipo de mente possível e questiona que seja com base nesse ideal de mente que definamos um conceito para o que é a mente humana. Esse enunciado, simples e direto, "eu não penso por palavras", toca em um pressuposto conhecido e bastante logocêntrico que atribui à linguagem, mais especificamente à linguagem verbal, representada pela palavra, o papel de instrumento, veículo ou organizador do pensamento e das relações humanas. Esse pressuposto já encontrou seus críticos e muitas pesquisas e reflexões já se inclinaram em outras direções para reconsiderar essa visão logocêntrica da linguagem frente ao pensamento. Mas ainda assim não são poucos os desafios quando, em nossas interações cotidianas, nos deparamos com uma situação em que as palavras e a conhecida organização linguística da língua materna que falamos não estão presentes da forma como estamos mais habituados (CRUZ, 2018, p. 191).

Na situação interativa analisada, Luiza organiza suas interações com recursos corporais, isto é, utiliza-se de gestos associados ou não a sua atividade de fala para interagir e mostra-se como uma interactante e falante pragmaticamente competente, apesar de apresentar restrições em sua linguagem verbal

Estamos assim em consonância com o que Delfrate, Santana e Massi (2009) constataram. Segundo estes autores, no quadro do TEA cada sujeito exige uma compreensão e análise individual, pois as características da síndrome variam de acordo com cada caso e as dificuldades individuais são muito diferentes. Há algo da ordem de um déficit e alterações da linguagem na criança com TEA de modo geral. No entanto, é preciso levar em conta a complexidade envolvida em vários mecanismos de significação para compreender o que a criança, dentro dessa condição particular, consegue apreender do mundo e das interações, apesar de suas dificuldades particulares. 
Devido a análise multimodal deste excerto interativo foi possível identificar que Luiza mostrou-se capaz de: coordenar várias ações e multiatividades, ajustando-se a uma dinâmica interacional e acompanhando as distintas práticas de atenção que se estabelecem; sustentar seus turnos de fala corporalmente até que atinja sua(s) intencionalidade(s) pragmática(s); mobilizar diferentes recursos semióticos para construir localmente uma ação relevante na interação; e sustentar sequências conversacionais por meio da utilização de recursos multimodais para engajar-se na construção e negociação de sentidos.

\section{Considerações finais}

Neste artigo adotamos um método de descrição analítica do excerto selecionado fundamentados numa abordagem teórica e procedimental para o estudo da organização social da interação com foco nos recursos linguístico-gestuais mobilizados por uma criança com TEA em uma interação familiar em ambiente naturalístico. Assim, identificamos unidades multimodais para entender a interação.

Especificamente, construímos uma coleção de dados multimodais com as produções de Luiza extraídas de uma interação cotidiana, com o propósito de elencar e de dar visibilidade às variabilidades funcionais e significativas que essas unidades linguístico-gestuais exercem no decorrer do contexto situacional em que se desenrolam.

Os achados da análise empreendida sugerem, portanto, que Luiza, embora possua algumas restrições do ponto de vista dos recursos verbais os mobiliza de modo articulado a recursos não-verbais para construir e participar de situações interativocomunicacionais. Esses achados permitem considerar a produtividade de se analisar os dados em busca de Gestalts (padrões) Multimodais (gestos/postura + fala) identificados no repertório sociointeracional de Luiza. Esta investigação multimodal 
possibilitou dar visibilidade a uma gama de recursos verbais e não-verbais empregados por este sujeito.

Esperamos, por fim, que o estudo apresentado possa oferecer subsídios importantes para o entendimento da forma como os sujeitos com TEA interagem e como os outros interlocutores interagem com eles, proporcionando um aprofundamento das perspectivas sobre habilidades comunicativas e sociais no transtorno.

\section{Referências}

ANDRADE, C. K. S. Linguagem e autismo: a multimodalidade no contexto escolar. 2017. 148 f. Dissertação (Mestrado em Linguística) - Centro de Ciências Humanas, Letras e Artes, Universidade Federal da Paraíba, João Pessoa, 2017.

AUBURN, T.; POLLOCK, C. Laughter and competence: children with severe autism using laughter to joke and tease. In: GLENN, P.; HOLT, E. Studies of laughter in interaction. London: Bloomsbury, 2013. p. 135-160.

AUER, P. On-line syntax: thoughts on the temporality of spoken language. Language sciences, v. 31, n. 1, p. 1-13, 2009. DOI https://doi.org/10.1016/j.langsci.2007.10.004.

AUER, P. The temporality of language in interaction: projection and latency. In: DEPPERMANN, A.; GÜNTHNER, S. D. (ed.). Studies in language and social interaction, v. 27, p. 27-56, 2015. DOI https://doi.org/10.1075/slsi.27.01aue.

BRAIT, B. O processo interacional. In: PRETI, D. (org.) Análise de textos orais. Humanitas: São Paulo, 2010.

COTS, C. P. Quando a linguagem verbal se ausenta, o que há? Relatório Final de Pesquisa. Fundação de Amparo à Pesquisa do Estado de São Paulo. Pesquisa Fapesp 14/15206-6, São Paulo, 2015.

COTS, C. P. Recursos interacionais multimodais mobilizados por uma criança com TEA em brincadeiras familiares. 2018. 141 f. Dissertação (Mestrado em Letras) Escola de Filosofia, Letras e Ciências Humanas, Universidade Federal de São Paulo, Guarulhos, 2018. 
CRUZ, F. M. Interação corporificada: multimodalidade, corpo e cognição explorados na análise de conversas envolvendo sujeitos com Alzheimer. Alfa, São Paulo, v. 61, n. 1, p. 55-80, 2017a. DOI https://doi.org/10.1590/1981-5794-1704-3.

CRUZ, F. M. Elementos para uma análise multimodal da interação: um exemplo de correlação linguístico-gestual no autismo. In: Multimodalidade nos estudos discursivos. Trabalho apresentado no VIII EPED (Encontro de Pós-graduandos Universidade de São Paulo/USP), p. 158-179, 2017b.

CRUZ, F. M. Documentação e investigação multimodal de interações envolvendo crianças com autismo: corpo, linguagem e mundo material. Revista Calidoscópio Unisinos, São Leopoldo, v. 16, n. 2, p. 179-193, mai/ago, 2018. DOI https://doi.org/10.4013/cld.2018.162.01.

DELFRATE, C. B.; SANTANA, A. P. O.; MASSI, G. A. A aquisição de linguagem na criança com autismo: um estudo de caso. Psicologia em estudo, Maringá, v. 14, n. 2, p. 321-331, abr./jun, 2009. DOI https://doi.org/10.1590/S1413-73722009000200013.

DINDAR, K.; KORKIAKANGAS, T.; LAITILA, A.; KÄRN ̈̈, E. Facilitating joint attention with salient pointing in interactions involving children with autism spectrum disorder. Gesture, v. 15, n. 3, p. 372-403, 2016. DOI https://doi.org/10.1075/gest.15.3.06din.

ENFIELD, N. The body as a cognitive artifact in inship representations: hand gesture diagrams by speakers of Lao. Current Anthropology, v. 46, n.1, p. 1-26, 2005.

FENG, H. Studying eye gaze of children with autism spectrum disorders in interaction with a social robot. 2014. $112 \mathrm{f}$. Thesis (Degree master of Science) - Faculty of the Daniel Felix Ritchie School of Engineering and Computer Science, University of Denver, Denver, 2014. Disponível em:

https://digitalcommons.du.edu/cgi/viewcontent.cgi?article=1192\&context=etd. Acesso em: 31 mar. 2019.

GLENN, P. Laughter in interaction. New York: Cambridge University Press, 2003. DOI https://doi.org/10.1017/CBO9780511519888.

GOODWIN, C. Conversational organization: interaction between speakers and hearers. New York: Academic Press, 1981. 
GOODWIN, C. Things and their embodied environments. In: LAMBROS, M.; RENFREW, C. (ed.). The cognitive life of things: recasting boundaries of the mind. Cambridge, UK, McDonald Institute for Archaeological Research, 2010. p. 103-120.

GRANDIN, T. Thinking in pictures: and other reports from my life with autism. New York: Vintage Books, 1996. 240 p.

JEFFERSON, G. A technique for inviting laughter and its subsequent acceptance declination. In: PSATHAS, G. (ed.). Everyday language: studies in ethnomethodology. New York: Irvington, 1979. p. 79-96.

KENDON, A. Gesture: visible actions as utterance. Cambridge: Cambridge University Press, 2004. DOI https://doi.org/10.1017/CBO9780511807572.

KLEPPA, L. Estruturas de tópico-comentário na fala reduzida de um sujeito afásico. Estudos linguísticos, São Paulo, v. 43, n. 2, p. 926-939, maio-ago. 2014.

KORKIAKANGAS, T.; RAE, J. The interactional use of eye-gaze in children with autism spectrum disorders. Interaction studies, v. 15, n. 2, p. 233-259, 2014. DOI https://doi.org/10.1075/is.15.2.12kor.

LAI, M. C.; LOMBARDO, M.; BARON-COHEN, S. Autism. The lancet, v. 383, n. 9920, p. 896-910, 2014. DOI https://doi.org/10.1016/S0140-6736(13)61539-1.

LEVINSON S. C.; HOLLER J. The origin of human multi-modal communication. Philosophical. Transactions of the Royal Society, v. 369, n. 1651, 2014. DOI https://doi.org/10.1098/rstb.2013.0302.

LIMA, C. V.; REHBERG, L. L. A multimodalidade da linguagem e os transtornos do espectro do autismo (TEA) num contexto terapêutico semidirigido. In: CAETANO, S.; LIMA-HERNANDES, M. C.; PAULA, F.; RESENDE, B. D.; MÓDOLO, M. (org.). Autismo, linguagem e cognição. 1. ed. Jundiaí: Paco Editorial, 2016. v. 1, p. 57-82.

MIGUENS, S. Conceito de crença, triangulações e atenção conjunta. In: MIGUENS, S.; MAURO, C. E. E. (ed.). Perspectives on rationality, Porto, Universidade do Porto Faculdade de Letras, p. 99-118, 2006.

MONDADA, L. A referência como trabalho interativo: a construção da visibilidade do detalhe anatômico durante uma operação cirúrgica. In: KOCH, I. V.; MORATO, E. M.; BENTES, A. C. (org.). Referenciação e discurso. São Paulo: Contexto, 2005. p. 11-31. 
MONDADA, L. Organisation multimodale de la parole-en-interaction: pratiques incarnées d'introduction des referents. Langue française, n. 175, p. 129-147, 2012. DOI https://doi.org/10.3917/lf.175.0129. Disponível em: https://www.cairn.info/revuelangue-francaise-2012-3-page-129.htm. Acesso em: 31 mar. 2019.

MONDADA, L. The local constitution of multimodal resources for social interaction. Journal of pragmatics, v. 65, p. 137-156, 2014a. DOI https://doi.org/10.1016/j.pragma.2014.04.004. Disponível em: https://www.sciencedirect.com/science/article/abs/pii/S0378216614000794?via\%3Dihu b. Acesso em: 31 mar. 2019.

MONDADA, L. Pointing, talk, and the bodies: reference and joint attention as embodied interactional achievements. In: SEYFEDDINIPUR, M.; GULLBERG, M. (org.). From gesture in conversation to visible action as utterance: Essays in honor of Adam Kendon. London: John Benjamins Publishing Company, 2014b. p. 95-124. DOI https://doi.org/10.1075/z.188.06mon.

MONDADA, L. Challenges of multimodality: Language and the body in social interaction. Journal of Sociolinguistics, v. 20, n. 3, 2016. DOI https://doi.org/10.1111/josl.1_12177. Disponível em: https://onlinelibrary.wiley.com/doi/full/10.1111/josl.1 12177. Acesso em: 31 mar. 2019.

SELTING, M. The construction of units in conversational talk. In: SELTING, M. Language in society, Cambridge University Press, v. 29, p. 477-517, 2000. DOI https://doi.org/10.1017/S0047404500004012.

SELTING, M. Syntax and prosody as methods for the construction and identification of turn-constructional units in conversation. In: SELTING, M.; HAKILINEN, A. (ed.). Syntax and lexis in conversation. Amsterdam: John Benjamins, 2005. p. 17-44. DOI https://doi.org/10.1075/sidag.17.04sel.

TOMASELLO, M. Joint attention as social cognition. In: MOORE, C.; DUNHAM, P. J. (ed.). Joint attention: its origins and role in development. Hillsdale, NJ: Erlbaum, 1995. p. 103-130.

TOMASELLO, M. Why we cooperate. Cambridge: MIT Press, 2009. DOI https://doi.org/10.7551/mitpress/8470.001.0001. 